A. Sharma · A. Sörenby · A. Wernerson - S. Efendic •

M. Kumagai-Braesch $\cdot$ A. Tibell

\title{
Exendin-4 treatment improves metabolic control after rat islet transplantation to athymic mice with streptozotocin-induced diabetes
}

Received: 1 November 2005 / Accepted: 27 January 2006 / Published online: 12 April 2006

(C) Springer-Verlag 2006

\begin{abstract}
Aims/hypothesis: Early islet graft survival is crucial in determining the outcome after clinical islet transplantation. Exendin-4 has anti-apoptotic and beta cell proliferative properties, which could improve islet graft survival and function. The aim of these studies was to evaluate the effect of exendin-4 on graft function after islet transplantation. Materials and methods: Rat islets were transplanted under the kidney capsule of diabetic athymic mice. First, we performed a dose-finding study and found that 30 islets just failed to cure diabetic mice. In the following two studies, we transplanted 30 islets and treated the mice that had received these islets with exendin-4 i.p. (100 ng/mouse) once daily for 1 week. Blood glucose levels and body weights were used as evaluation criteria. In the short-term study evaluation was done at day 8 . This study was followed by a long-term study that was evaluated at 4 weeks. In this study, islets were precultured with exendin- $4(0.1 \mathrm{nmol} / \mathrm{l})$ in addition to the treatment given to mouse-recipients of transplanted
\end{abstract}

A. Sharma and A. Sörenby contributed equally to this work.

A. Sharma · A. Sörenby · M. Kumagai-Braesch · A. Tibell CLINTEC, Division of Transplantation Surgery,

Karolinska Institutet,

Stockholm, Sweden

A. Wernerson

Department of Laboratory Medicine,

Division of Pathology,

Karolinska Institutet,

Stockholm, Sweden

S. Efendic

Department of Molecular Medicine,

Division of Endocrinology, Karolinska Institutet,

Stockholm, Sweden

A. Tibell $(\bowtie)$

Department of Transplantation Surgery, B56,

Karolinska University Hospital, Huddinge,

14186 Stockholm, Sweden

e-mail: annika.tibell@karolinska.se

Tel.: +46-858580000

Fax: +46-87467733 islets. The cured mice underwent an intraperitoneal glucose tolerance test (IPGTT). Results: In the shortterm study, $63 \%$ of exendin-4-treated mice achieved graft function compared with $21 \%$ of untreated mice $(p=0.033)$. In the long-term study, $88 \%$ of treated mice had functioning grafts compared with $22 \%$ of controls $(p=0.015)$. Cured mice showed a normal response in the IPGTT, comparable to that of healthy mice. Exendin-4treated mice gained significantly more weight than their untreated counterparts. Conclusions/interpretation: Islet preculture and a short course of therapy with exendin-4 improves metabolic control after rat islet transplantation in athymic mice. The beneficial effect lasts beyond the treatment period.

Keywords Diabetes - Exendin-4 - Experimental · GLP-1 · Islet transplantation

Abbreviations GLP-1: glucagon-like peptide-1 . IPGTT : intraperitoneal glucose tolerance test

\section{Introduction}

Recent advances in clinical protocols have improved the outcome of pancreatic islet transplantation [1]. However, islet recipients typically require islet grafts derived from multiple donors to achieve insulin independence. If diabetes reversal could be achieved with a single donor, it would reduce costs and increase the availability of the islet transplantation procedure [2]. In the immediate posttransplantation period, a significant part of the graft is destroyed by the so-called instant blood-mediated inflammatory reaction [3]. The islet mass may diminish further as a result of hypoxia and hyperglycaemia. It has been shown in experimental models of syngeneic islet transplantation that nearly $60 \%$ of pancreatic islets undergo apoptosis in the early post-transplantation period. Consequently, nonalloantigen-specific inflammatory events seem to be important in early graft destruction [4]. To confer protection on islets, various agents have been proposed 
for the pretreatment of donors [5], the culturing of islets [6] or the treatment of recipients $[3,7,8]$ after transplantation, but the number of clinical studies to date is limited.

Glucagon-like peptide-1 (GLP-1) and its long-lasting analogue exendin-4 can significantly improve glycaemic control in patients with type 2 diabetes mellitus [9]. Exendin-4 has beneficial effects on postprandial blood glucose levels in patients with type 1 diabetes [10]. GLP-1 and exendin-4 inhibit cell apoptosis [11] and increase beta cell mass $[12,13]$. A recent study has shown that, in a syngeneic mouse model, islets precultured with exendin-4 had a higher rate of reversal of hyperglycaemia than islets cultured without the drug [14].

In our study, a suboptimal number of rat islets was transplanted into athymic mice with streptozotocin-induced diabetes. The model was designed to mimic the clinical situation of islet transplantation, where often suboptimal islet doses are transplanted and insulin therapy is given to protect the graft in the early post-transplant period. The aim of our study was to evaluate whether the actions of exendin- 4 would improve the metabolic outcome after transplantation of a suboptimal mass of islets.

\section{Materials and methods}

Animal care

The local animal ethics committee approved the studies. All animals were kept according to the requirements of the Animal Welfare Act and the National Institutes of Health guidelines for the care and use of laboratory animals.

\section{Rat islet isolation}

Male Sprague-Dawley rats (Scanbur, Sollentuna, Sweden) weighing $300 \mathrm{~g}$ were used as islet donors. Rat pancreases were removed under inhalation anaesthesia using enflurane and animals were killed by bleeding. Islets were prepared using the intraductal collagenase digestion technique using $2 \mathrm{mg} / \mathrm{ml}$ collagenase V (Sigma-Aldrich, St Louis, MO, USA). Islets were purified by discontinuous density gradient centrifugation (Histopaque-119, Sigma-Aldrich; and Lymphoprep, Axis-Shield, Oslo, Norway) and handpicked. Isolated islets were cultured overnight in RPMI 1640 medium, pH 7.4 (Gibco BRL Life Technologies, Paisley, UK), supplemented with $10 \%$ fetal calf serum, $2 \mathrm{mmol} / 1 \mathrm{~L}$-glutamine, $50 \mathrm{U} / \mathrm{ml}$ penicillin and $50 \mathrm{mg} / \mathrm{ml}$ streptomycin (all from Gibco), in a humidified atmosphere of $5 \% \mathrm{CO}_{2}$ in air at $37^{\circ} \mathrm{C}$. The following day, the islets were washed with Hanks' Balanced Salt Solution (Karolinska University Hospital, Stockholm, Sweden), hand-picked and transplanted to diabetic mice randomly between the study groups. Transplanted islet purity was approximately $90 \%$.
Mouse preparation and islet transplantation

Male inbred athymic mice (nu/nu Black 6; Taconic M\&B, Ry, Denmark) weighing $25 \mathrm{~g}$ were used as recipients. Diabetes was induced by injection of streptozotocin (Sigma-Aldrich), $250 \mathrm{mg} / \mathrm{kg}$ body weight, into the penile vein under inhalation anaesthesia using enflurane. An animal was considered diabetic if its blood glucose level exceeded $20 \mathrm{mmol} / \mathrm{l}(>360 \mathrm{mg} / \mathrm{dl})$ for two or more consecutive days. Islets were then transplanted under the kidney capsule under inhalation anaesthesia.

\section{Definition of metabolic control}

On follow-up, sustained non-fasting blood glucose levels of $10 \mathrm{mmol} / 1$ or below were defined as cure, $11-20 \mathrm{mmol} / \mathrm{l}$ as partial function of transplanted islets and levels above $20 \mathrm{mmol} / \mathrm{l}$ as graft failure.

Determination of suboptimal islet number

A cut-off islet number that just failed to cure diabetic mice was determined by progressively decreasing the number of transplanted islets from 75 to 50 and then 30 . We found that, in our model, 50 islets repeatedly cured diabetic mice while 30 islets did not (Table 1). Transplantation of 35-45 islets resulted in partial control of the diabetic state (data not shown).

\section{Short-term study}

Animals were followed for 8 days. They were divided into five groups: (1) 30 islets with exendin-4 treatment (AnaSpec; San Jose, CA, USA); (2) 30 islets without treatment; (3) 75 islets without treatment (quality controls); (4) non-transplanted diabetic mice treated with exendin-4; and (5) non-transplanted diabetic mice without treatment. Exendin-4 was given as a single i.p. injection of $100 \mathrm{ng}$ (approximately $24 \mathrm{pmol}$ ) per day from day 0 to day 7 . Mice that were euglycaemic had grafts removed and were followed for a few more days. Once diabetic, they were killed and the pancreases were removed for histology.

Table 1 Determination of the suboptimal islet number that fails to cure diabetic mice

\begin{tabular}{llll}
\hline & 75 islets & 50 islets & 30 islets \\
\hline$n$ & 4 & 5 & 4 \\
Cure & 4 & 4 & 0 \\
Partial function & 0 & 1 & 0 \\
Non-cure & 0 & 0 & 4 \\
\hline
\end{tabular}


Long-term study

The mice were observed for 4 weeks. As in the short-term study, exendin-4 was given for 8 days. Animals were divided into three groups: (1) 30 islets with temporary exendin-4 treatment; (2) 30 islets without exendin-4 treatment; and (3) 75 islets without treatment (quality controls). In group-1, exendin-4 $(0.1 \mathrm{nmol} / \mathrm{l})$ was added to the culture medium $20 \mathrm{~h}$ before transplantation of islets. At 4 weeks, the cured mice were subjected to an intraperitoneal glucose tolerance test (IPGTT). Two to three days later, grafts were removed to confirm the recurrence of diabetes and then the mice were killed. One mouse that remained euglycaemic after graft removal was discarded from the study. Non-cured animals were killed earlier if they became very weak during the observation period. All grafts and native pancreases were removed for histological examination.

\section{Post-transplant management}

In both studies, the non-fasting blood glucose levels and weights of the animals were measured daily during the first week before administering exendin-4 i.p. Thereafter, mice with blood glucose levels below $10 \mathrm{mmol} / \mathrm{l}$ for $2-3$ consecutive days were assessed twice a week. Mice with hyperglycaemia were checked daily and given a mixture of short- and long-acting human recombinant insulin (Actrapid and Ultratard; Novo Nordisk, Bagsvaerd, Denmark) in equal proportions s.c. once a day, after the measurement of blood glucose. A total of $2 \mathrm{U}$ was given for blood glucose levels of $11-20 \mathrm{mmol} / \mathrm{l}$ and $4 \mathrm{U}$ for levels above $20 \mathrm{mmol} / \mathrm{l}$. If a normalised blood glucose level was detected, the insulin treatment was omitted that day.

Intraperitoneal glucose tolerance test

Mice were fasted for at least $6 \mathrm{~h}$ before examination. A $20 \%$ glucose solution was given at $10 \mu \mathrm{l} / \mathrm{g}$ i.p. and blood glucose was measured before injection and $5,10,15,20$, $30,45,60,90$ and 120 min after injection. Healthy mice were used as normal controls and tested at the same time.

\section{Histological studies}

Graft-bearing kidneys and the native pancreases were immediately fixed in $4 \%$ phosphate-buffered formalin after explantation. They were then dehydrated, embedded in paraffin and cut into $3 \mu \mathrm{m}$ thick sections with a microtome (Rotary Microtome; Microm International, Walldorf, Germany). The sections were stained with haematoxylin and eosin. Immunohistochemical staining was also performed for detection of insulin-containing cells (guinea-pig anti-insulin antibody; Dako, Carpinteria, CA, USA). Single sections from grafts and pancreases were evaluated semiquantitatively for comparison of insulin-positive cells and islets, respectively.

Statistical methods

The proportions of cured animals in each group were compared using the two-tailed Fisher's exact test. Insulin requirement and body weight gains are presented as mean \pm SD and were compared using the unpaired Student's $t$-test. Differences were considered to be statistically significant if $p<0.05$.

\section{Results}

Short-term study

Results are shown in Table 2. In the exendin-4-treated group, $63 \%$ of mice developed function of transplanted islets compared with $21 \%$ in the control group $(p=0.033)$. In the treated group, 5/16 mice were completely cured while 5/16 had partial graft function. The mean insulin requirement was significantly lower in the exendin-4-treated mice than in the untreated mice $(1.9 \pm 1.1$ vs $3.2 \pm 1.0 \mathrm{U} /$ day, $p=0.001)$. During the 8 days of observation, the treated group gained significantly more weight compared with the control group $(2.0 \pm 1.3$ vs $1.1 \pm 0.9 \mathrm{~g}, p=0.031)$. Mice that did not receive any islets but were treated with exendin-4 and insulin remained diabetic. The histological examinations of pancreases from these exendin-4-treated-mice $(n=5)$ were similar to those of diabetic untreated mice $(n=4)$ with no insulin-positive cells, except for one stained islet in one section in the treated group. Pancreases of normal nude mice $(n=3)$ showed more than 15 stained islets per section.

\section{Long-term study}

Results are shown in Table 3. When evaluated at 4 weeks, $7 / 8$ animals treated with exendin- 4 had graft function compared with $2 / 9$ in the control group $(p=0.015)$. Blood sugar levels during the follow-up period indicated complete cure in six, partial function in one and graft failure in one of the animals in the treated group (Fig. 1). In

Table 2 Short-term effect of exendin-4 on transplanted islets

\begin{tabular}{|c|c|c|c|}
\hline & 30 islets + exendin- 4 & 30 islets & $p$ \\
\hline$n$ & 16 & 14 & \\
\hline Cure & 5 & 0 & \\
\hline Partial function & 5 & 3 & \\
\hline Graft function $^{\mathrm{a}}$ & $63 \%$ & $21 \%$ & 0.033 \\
\hline Insulin/day (U) & $1.9 \pm 1.1$ & $3.2 \pm 1.0$ & 0.001 \\
\hline Weight gain $(\mathrm{g})$ & $2.0 \pm 1.3$ & $1.1 \pm 0.9$ & 0.031 \\
\hline
\end{tabular}

${ }^{\mathrm{a}} \mathrm{Graft}$ function $=$ cure + partial function 
Table 3 Long-term effect of exendin-4 on transplanted islets

\begin{tabular}{|c|c|c|c|}
\hline & 30 islets + exendin -4 & 30 islets & $p$ \\
\hline$n$ & 8 & 9 & \\
\hline Cure & 6 & 1 & \\
\hline Partial function & 1 & 1 & \\
\hline Graft function ${ }^{a}$ & $87 \%$ & $22 \%$ & 0.015 \\
\hline Normal IPGTT & 6 & 1 & 0.015 \\
\hline Weight gain $(\mathrm{g})$ & $4.1 \pm 1.0$ & $1.6 \pm 1.7$ & 0.001 \\
\hline
\end{tabular}

${ }^{\mathrm{a}} \mathrm{Graft}$ function $=$ cure + partial function

the control group, blood sugar levels were normalised in one and in the partial function range in one; the other seven animals remained diabetic (Fig. 1). All cured animals showed a normal response in the IPGTT, comparable to that of normal healthy mice (Fig. 2). The average weight gained by the exendin-4-treated mice over this 4-week period was significantly higher than in the untreated mice $(4.1 \pm 1.0$ vs $1.6 \pm 1.7 \mathrm{~g}, p=0.001)$. Histopathological examination of the grafts from cured animals showed prominent, viable, insulin-stained cells under the kidney capsule. Grafts from cured animals showed larger amounts of insulin-stained cells than grafts from non-cured animals. Typical grafts stained for insulin from cured and non-cured animals $(n=3$ each) are shown in Fig. 3. The pancreas sections from all recipient mice showed no or a few weakly insulin-stained islets (data not shown).

\section{Discussion}

In the present studies, we have shown that exendin- 4 treatment improves metabolic control after transplantation of a suboptimal islet number. Exendin-4 is a GLP-1 agonist that binds to and activates the GLP-1 receptor $[15,16]$. Exendin-4 has a longer duration of action than GLP-1 because of resistance to degradation by the enzyme dipeptidyl peptidase IV [17]. It is known that exendin-4 causes glucose-dependent stimulation of insulin secretion, suppression of glucagon secretion, slowing of gastric emptying, inhibition of food intake, modulation of glucose
Fig. 1 Non-fasting blood glucose concentrations after islet transplantation of the exendin4-treated group (a) and the non-treated group (b) in the long-term study. Bold, solid lines with diamonds, cure $(n=6$ in $\mathbf{a}, n=1$ in b); broken lines with triangles, partial graft function $(n=1$ in $\mathbf{a}$ and $\mathbf{b})$; thin solid lines with squares, non-functioning grafts $(n=1$ in $\mathbf{a}, n=7$ in b). The standard deviation (a) of the cured animals is larger on day 20 because a single animal showed a high blood glucose concentration on that day. However, it recovered fully within 5 days. Arrows indicate day of graft removal

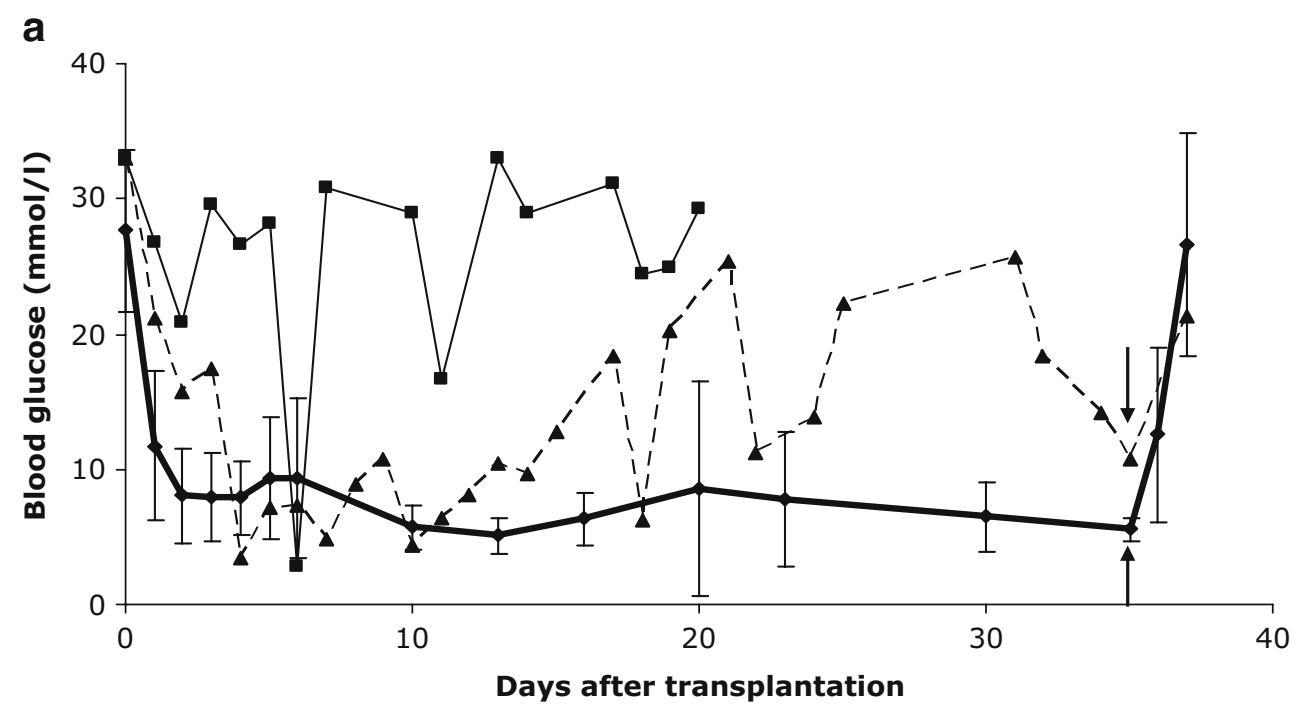

b

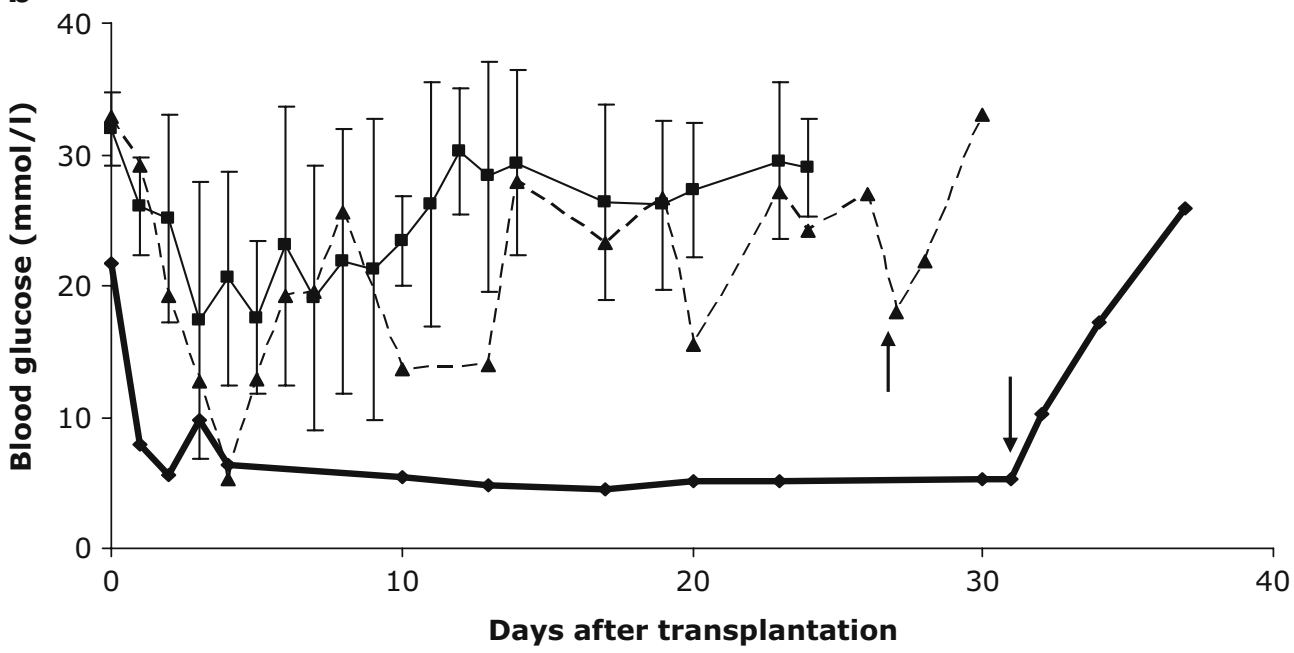


Fig. 2 IPGTT of cured exendin4-treated mice ( $n=6$, solid line) and normal healthy controls $(n=7$, broken line). Mean values \pm SD for the two groups are shown

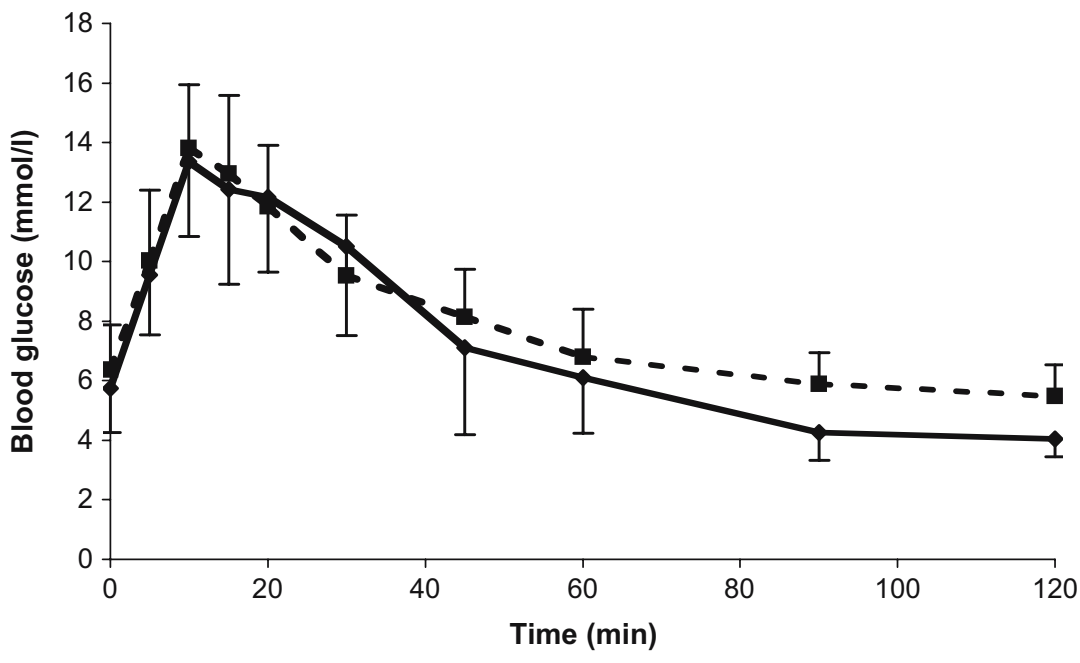

trafficking in the peripheral tissues and enhancement of beta cell mass [9]. In our short-term study, exendin-4treated islet recipients had significantly better metabolic

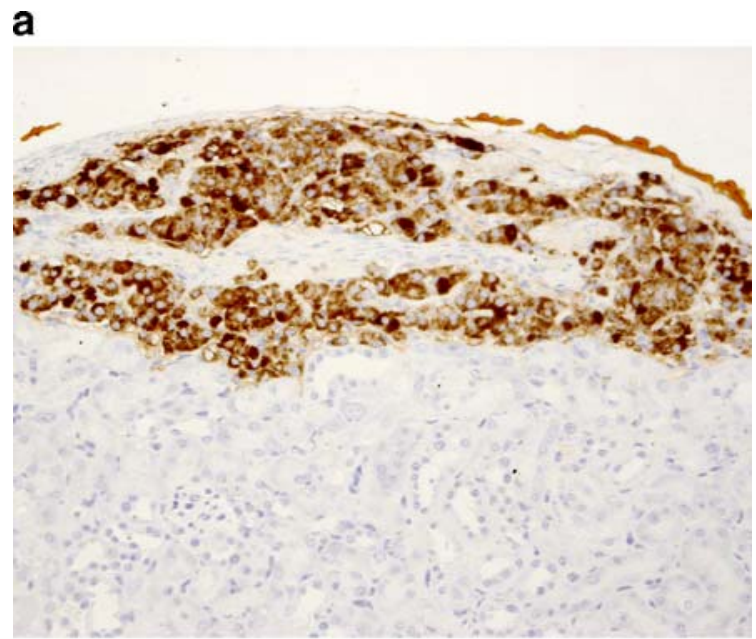

b

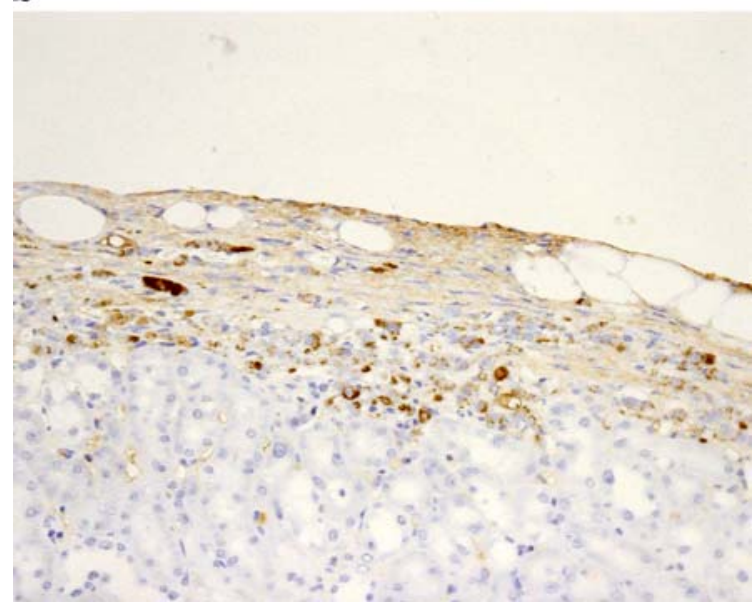

Fig. 3 Immunohistochemical staining for insulin from an exendin-4treated (a) and a non-treated (b) animal showing positive cells (brown colour) under the kidney capsule (original magnification $\times 20$ ) control compared with the control group. The long-term study showed that this benefit lasted beyond the exendin-4 treatment period. This suggests that the effect of exendin-4 could be attributed to its actions on the graft itself, rather than its peripheral actions. This was also indicated in the histological examination where a larger amount of insulinpositive cells was observed in the exendin-4-treated group. The cured mice in our study exhibited normal responses to IPGTT, suggesting that, once the suboptimal islet mass survives the initial setbacks, it attains a stable physiological function comparable to that found in non-diabetic mice. Although exendin- 4 is known to have anorectic actions, the treated mice followed normal weight curves after transplantation and had significantly higher weight gain compared with non-treated diabetic mice.

The exendin-4 treatment may increase the risk of return of native pancreas function in animals with chemically induced diabetes. It was shown previously that when exendin-4 was administered together with low-dose streptozotocin in newborn rats, beta cell mass had increased at day 7 and persisted at 2 months of age [18]. This was attributed to both enhanced beta cell proliferation and an increased number of small budding islets in the pancreas. In our study, exendin-4 treatment alone did not improve the metabolic control of non-transplanted mice with streptozotocin-induced diabetes. Furthermore, the histopathological examination of the native pancreases from these mice generally did not show any insulin-stained islets at 1 week. All animals cured by islet transplantation became diabetic after graft removal, suggesting that there was no significant regeneration of the native pancreas. In addition, histological examination of the native pancreases from the long-term study showed only a few weakly stained islets compared with the high numbers of wellstained islets in the normal pancreas.

In a recently published study by King et al. on exendin-4 in islet transplantation, it was shown that cure rates improved if the islet cells were precultured with exendin-4 [14]. However, fresh untreated islets were even more efficient. In that syngeneic mouse model, transplantation of 150 islets resulted in a mean time to cure of 31 days with 
fresh islets, 58 days with exendin-4-precultured islets and 81 days using islets cultured without exendin-4. Exendin-4 treatment of the recipients did not improve the outcomes further. We analysed the effect of exendin- 4 in a somewhat different setting. In our short-term study, recipient treatment with exendin- 4 improved metabolic control of the animals. If we compare the cure rates after 1 week in our short-term study (recipient treatment only) and long-term study (preculture of islets and recipient treatment), the results suggest that a combination of preculture and recipient treatment is more effective than treatment of recipients alone. However, the study protocol was not designed to evaluate the effect of preculture alone. Furthermore, our study is not directly comparable with the study by King et al.; for instance, we used different animal models and different culture conditions. In our study, islets were cultured for $20 \mathrm{~h}$ in a medium containing $0.1 \mathrm{nmol} / 1$ exendin- 4 , whereas in the previous study islets were cultured for $72 \mathrm{~h}$ at a concentration of $1.0 \mathrm{nmol} / \mathrm{l}$. Time to cure also differed significantly between the two studies. We transplanted only 30 rat islets to the mice, and even so the time to cure was shorter. However, rat islets are larger than mice islets [19] and the viability may have been better because of our shorter culture time. Longer culture has been shown to increase islet hypoxia and central necrosis of islets [20], and may also affect the viability of the intra-islet endothelial cells, which are important for the revascularisation of grafts [21]. In spite of some differences in results, both studies support the idea that exendin-4 has beneficial effects on islet transplant outcome. Exendin-4 may have various effects during different steps of engraftment, and therefore optimal dosing and timing of exendin-4 treatment require further evaluation.

In our study, rat islets were transplanted to athymic mice. We chose this model since we wanted to study early graft damage in the absence of a rejection response. It is known that factors like hypoxia, non-specific inflammation and hyperglycaemia can contribute to early graft damage. During the isolation, culture and transplantation procedures, islets are exposed to cytokines from cells of both donor and recipient origin. The resident macrophages, tissue-infiltrating leucocytes, the islets themselves and damaged recipient tissues are sources of inflammatory mediators, which could trigger islet apoptosis and result in early graft losses [4]. The athymic mouse is unable to reject allo- and xenogeneic islet grafts; however, the strain still retains the ability to mediate a strong non-specific inflammatory response [22-24]. To our knowledge, there are no species-specific differences described concerning the effects of exendin-4. Taken together, we believe that the results from our model can contribute to knowledge of the effects of exendin-4 during early islet engraftment.

As discussed above, various inflammatory factors, such as IL-1, TNF- $\alpha$ and IFN- $\gamma$, produced during islet isolation, culture and surgical procedures, may cause islet loss by induction of apoptosis. Exendin- 4 has been shown to protect beta cells from apoptosis induced by these cytokines in vitro [25]. A recent in vitro study on cultured human islets showed that GLP-1 inhibited apoptosis during the 5 days of observation [26]. Another in vitro study showed that pretreatment of mouse insulinoma cells with GLP-1 prevented apoptosis, whereas the drug was unable to rescue already apoptotic cells [27]. The authors therefore concluded that GLP-1 acts through the induction of cellular anti-apoptotic proteins by increasing their expression or activity. This finding suggests that early graft treatment is crucial in preventing apoptosis after islet transplantation. Other studies have shown that GLP-1 receptor signalling is coupled to the formation of new beta cells through enhanced proliferation of existing beta cells [28] and the induction of islet neogenesis [12]. These regenerative and anti-apoptotic properties of exendin-4 could explain the results of our long-term study, in which the improved metabolic control lasted after the exendin-4 treatment period.

Other drugs have also been studied for protection of islets. It has been shown that nicotinamide added to the culture medium reduces the expression of islet tissue factor and monocyte chemotactic factor, thereby decreasing the islet damage caused by the instant blood-mediated inflammatory reaction [29]. When lisofylline is added to the culture medium of human islets, inflammatory damage is prevented and islet viability and function improve [6]. Exendin-4 may be an interesting clinical alternative. The pharmacodynamics and safety of exendin- 4 have been tested successfully in phase $2[30,31]$ and phase 3 trials in type 2 diabetes mellitus. The compound was recently introduced in the treatment of type 2 diabetes mellitus in the USA.

Our observations indicate that islet preculture and recipient treatment with exendin-4 has beneficial longterm effects on metabolic control after transplantation of a suboptimal number of islets. Further studies are needed to fully elucidate the mechanisms of exendin- 4 that predominate in the islet transplantation setting. It would also be of clinical relevance to analyse the effects of exendin-4 administration when allogeneic islets are transplanted into the portal vein.

Acknowledgements The studies were supported by Foundation for International Surgical Cooperation and research grants from Karolinska Institute and Swedish Research Council (project number 52120016460). We thank B. Nilsson for statistical advice and A. Hansson for technical assistance.

\section{References}

1. Shapiro AM, Lakey JR, Ryan EA et al (2000) Islet transplantation in seven patients with type 1 diabetes mellitus using a glucocorticoid-free immunosuppressive regimen. N Engl J Med 343:230-238

2. Hering BJ, Matsumoto I, Sawada T et al (2002) Impact of twolayer pancreas preservation on islet isolation and transplantation. Transplantation 74:1813-1816

3. Bennet W, Sundberg B, Groth CG et al (1999) Incompatibility between human blood and isolated islets of Langerhans: a finding with implications for clinical intraportal islet transplantation? Diabetes 48:1907-1914 
4. Barshes NR, Wyllie S, Goss JA (2005) Inflammation-mediated dysfunction and apoptosis in pancreatic islet transplantation: implications for intrahepatic grafts. J Leukoc Biol 77:587-597

5. Juszczak MT, Hughes SJ, Jones GL, Powis SH, Press M (2004) Effect of donor treatment with heparinoids on graft function after intraportal transplantation of a marginal islet mass: an experimental study. Transplant Proc 36:3117-3120

6. Yang Z, Chen M, Ellett JD, Carter JD, Brayman KL, Nadler JL (2005) Inflammatory blockade improves human pancreatic islet function and viability. Am J Transplant 5:475-483

7. Ueki M, Yasunami Y, Motoyama K, Funakoshi A, Ikeda S, Tanaka M (1995) The amelioration of hyperglycemia in streptozotocin-induced diabetic rats after the intraportal transplantation of an insufficient number of islets by nicotinamide treatment. Transplantation 60:313-317

8. Sharma A, Kumagai-Braesch M, Sorenby A, Wernerson A, Efendic S, Tibell A (2005) Beneficial effects of exendin-4 treatment on metabolic control after transplantation of a suboptimal number of islets. Acta Diabetol 42:67-68

9. Gutniac M, Orskov C, Holst JJ, Ahren B, Efendic S (1992) Antidiabetogeneic effect of glucagon-like peptide-1 (7-36) amide in normal subjects and patients with diabetes mellitus. New Eng J Med 326:1316-1322

10. Dupre J, Behme MT, McDonald TJ (2004) Exendin-4 normalized postcibal glycemic excursions in type 1 diabetes. J Clin Endocrinol Metab 89:3469-3473

11. Urusova IA, Farilla L, Hui H, D’Amico E, Perfetti R (2004) GLP-1 inhibition of pancreatic islet cell apoptosis. Trends Endocrinol Metab 15:27-33

12. Xu G, Stoffers DA, Habener JF, Bonner-Weir S (1999) Exendin-4 stimulates both beta-cell replication and neogenesis, resulting in increased beta-cell mass and improved glucose tolerance in diabetic rats. Diabetes 48:2270-2276

13. Movassat J, Beattie GM, Lopez AD, Hayek A (2002) Exendin 4 up-regulates expression of PDX 1 and hastens differentiation and maturation of human fetal pancreatic cells. J Clin Endocrinol Metab 87:4775-4781

14. King A, Lock J, Xu G, Bonner-Weir S, Weir GC (2005) Islet transplantation outcomes in mice are better with fresh islets and exendin-4 treatment. Diabetologia 48:2074-2079

15. Eng J, Kleinman WA, Singh L, Singh G, Raufman JP (1992) Isolation and characterization of exendin-4, an exendin-3 analogue, from Heloderma suspectum venom. Further evidence for an exendin receptor on dispersed acini from guinea pig pancreas. J Biol Chem 267:7402-7405

16. Chen YE, Drucker DJ (1997) Tissue-specific expression of unique mRNAs that encode proglucagon-derived peptides or exendin 4 in the lizard. J Biol Chem 272:4108-4115

17. Kieffer TJ, McIntosh CH, Pederson RA (1995) Degradation of glucose-dependent insulinotropic polypeptide and truncated glucagon-like peptide 1 in vitro and in vivo by dipeptidyl peptidase IV. Endocrinology 136:3585-3596
18. Tourrel C, Bailbe D, Meile MJ, Kergoat M, Portha B (2001) Glucagon-like peptide-1 and exendin-4 stimulate beta-cell neogenesis in streptozotocin-treated newborn rats resulting in persistently improved glucose homeostasis at adult age. Diabetes 50:1562-1570

19. Sternesjo J, Sandler S (1998) Effects of interleukin-12 in vitro on pancreatic islets isolated from normal rodents and from nonobese diabetic mice. J Endocrinol 158:69-75

20. Olsson R, Carlsson PO (2005) Better vascular engraftment and function in pancreatic islets transplanted without prior culture. Diabetologia 48:469-476

21. Brissova M, Fowler M, Wiebe $P$ et al (2004) Intraislet endothelial cells contribute to revascularization of transplanted pancreatic islets. Diabetes 53:1318-1325

22. Normann S, Besedovsky H, Schardt M, del Ray A (1988) Interactions between endogenous glucocorticoids and inflammatory responses in normal and tumor-bearing mice: role of $\mathrm{T}$ cells. J Leukoc Biol 44:551-558

23. Dawson J, Hurtenbach U, MacKenzie A (1996) Cyclosporin A inhibits the in vivo production of interleukin-1beta and tumour necrosis factor alpha, but not interleukin-6, by a T-cellindependent mechanism. Cytokine 8:882-888

24. Kondo T, Morita K, Watarai Y et al (2000) Early increased chemokine expression and production in murine allogeneic skin grafts is mediated by natural killer cells. Transplantation 69:969-977

25. Li Y, Hansotia T, Yusta B, Ris F, Halban PA, Drucker DJ (2003) Glucagon-like peptide-1 receptor signaling modulates beta cell apoptosis. J Biol Chem 278:471-478

26. Farilla L, Bulotta A, Hirshberg B et al (2003) Glucagon-like peptide 1 inhibits cell apoptosis and improves glucose responsiveness of freshly isolated human islets. Endocrinology 144:5149-5158

27. Hui H, Nourparvar A, Zhao X, Perfetti R (2003) Glucagon-like peptide-1 inhibits apoptosis of insulin-secreting cells via a cyclic 5'-adenosine monophosphate-dependent protein kinase A- and a phosphatidylinositol 3-kinase-dependent pathway. Endocrinology 144:1444-1455

28. Edvell A, Lindstrom P (1999) Initiation of increased pancreatic islet growth in young normoglycemic mice (Umea $+/$ ?). Endocrinology 140:778-783

29. Moberg L, Olsson A, Berne C et al (2003) Nicotinamide inhibits tissue factor expression in isolated human pancreatic islets: implications for clinical islet transplantation. Transplantation 76:1285-1288

30. Nielsen LL, Baron AD (2003) Pharmacology of exenatide (synthetic exendin-4) for the treatment of type 2 diabetes. Curr Opin Investig Drugs 4:401-405

31. Fineman MS, Bicsak TA, Shen LZ et al (2003) Effect on glycemic control of exenatide (synthetic exendin-4) additive to existing metformin and/or sulfonylurea treatment in patients with type 2 diabetes. Diabetes Care 26:2370-2377 